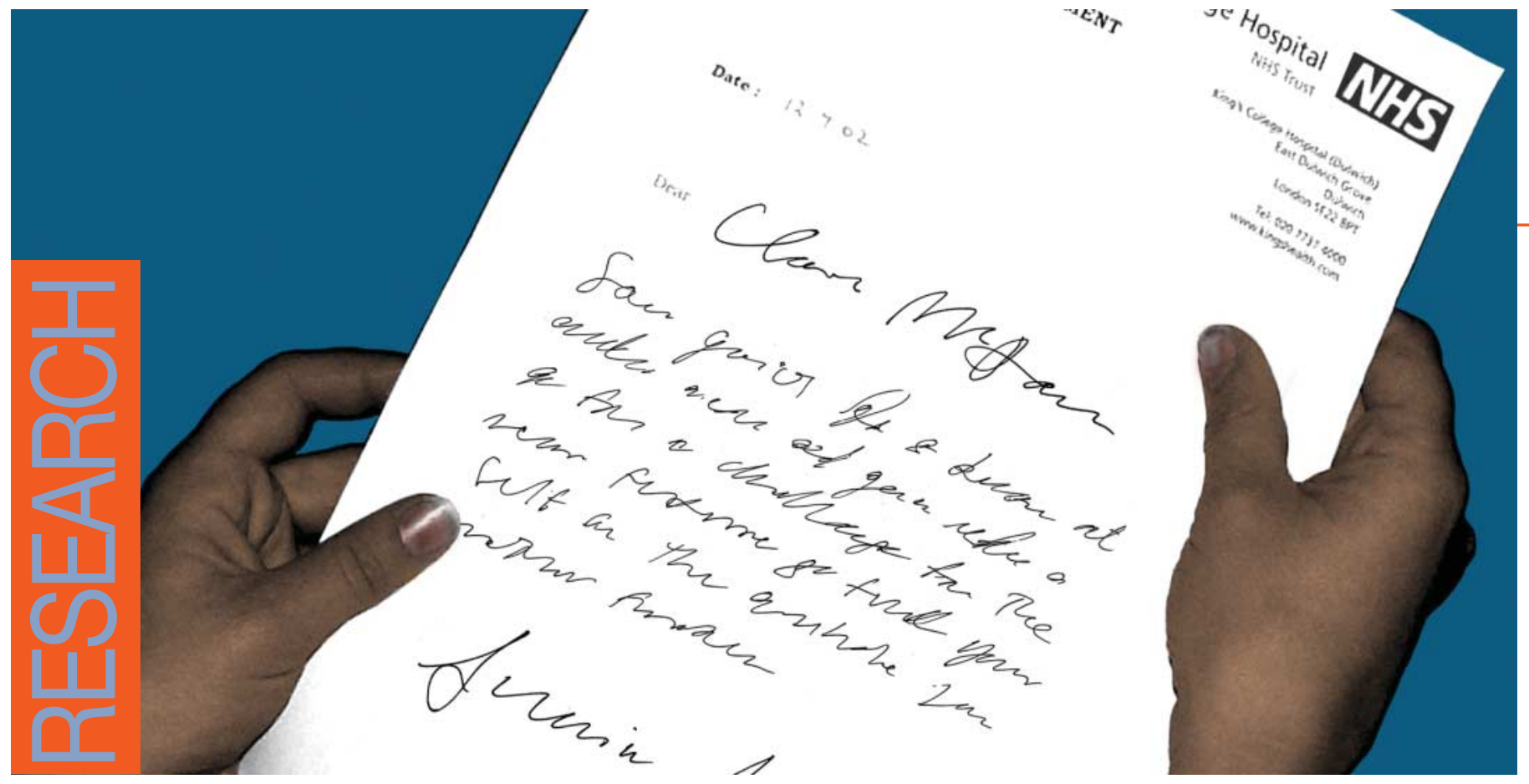

\title{
Do patients need to read research?
}

Most patients wouldn't dream of reading medical research. They probably imagine it to be arcane, mystical material full of numbers, formulas and Greek symbols. They aren't far wrong, but it is possible to get to grips with medical research without being as clever as Wittgenstein. If it's any comfort, most doctors don't read or understand medical research either-but they can be trained to do so without too much effort.

The main reason for reading medical research is that it underpins all of medicine. Increasingly, doctors are reluctant to use diagnostic methods and treatments unless they are based on good research. I belong to a generation who had our tonsils removed for recurrent snotty noses. The treatment was useless. Thirty years ago patients who had heart attacks were kept in bed for days. The treatment killed them. When my first son was born my wife was given an enema and had her pubic hair shaved. Both unnecessary. The history of medicine is mostly a history of ineffective and often dangerous treatments. This is what is meant by "evidence-based medicine." Unfortunately there is still no evidence to support most diagnostic methods and treatments. Either the research hasn't been done or it is of too poor a quality to be useful. Patients might want to read medical research in order to understand if evidence exists to support the treatments they are undergoing.

They might also want to read research in response to particular controversies-like, for example, the argument over whether the MMR (measles, mumps, rubella) vaccine causes autism. This idea arose from a scientifically weak study in the Lancet, which described a cluster of cases of children who had developed autism (and a strange bowel disorder) after being given the MMR vaccine. The problem is that virtually all children are given the vaccinewhich means hundreds of thousands a year-and all sorts of things will happen to them in the weeks after they have been given the vaccine. Some will break legs. Some will start to talk. Some may show signs of autism. But this doesn't mean that these events are caused by the vaccine.

I can't in a short piece convey everything you need to know to assess the validity of a piece of research, but I can give some guidance on one of medicine's most important-and simplest-questions: "Does a treatment work?" The simplest experiment would be to give a patient a treatment and see if it works-a case report. Such reports used to be common in medical journals, but we don't know what would have happened to the patient without the treatment. The same problem applies to a collection of patients: a case series, the most common type of study in many surgical journals.

\section{Intellectual experience}

The scientific answer to the problem is to have "control" patients who don't get the treatment. You might have a series of patients from before the treatment was available and compare what happened to them with a series of new patients given the treatment, known as a "before and after" study. There are two major problems with this: firstly, we don't know if the new patients are the same as the old patients; secondly, other things-perhaps the weather or the medical staff-might have changed and led to better results.

The best way to be sure that you are comparing the same sorts of patients at the same time is to "randomise" the patients to one treatment or another. To exclude "bias" (which might, for example, lead a doctor to put all the sicker patients into one arm of the trial) neither the doctor nor the patient should know who has got the active treatment, making the trial "double blind."

Because the benefit from most medical treatments is small and so hard to detect, you need very many patients in the trial. Although "double blind randomised trials" are the best way of working out whether a treatment works, many of them have not been well done and have given misleading results.

A final reason why patients might want to read medical research is because it's a satisfying intellectual experience-like reading Proust or trying to make sense of the paintings of Titian.

\section{Further reading}

To learn more about how to work out whether a piece of medical research is reliable, read Trisha Greenhalgh's book, How to Read a Paper, available from the BMJ Bookshop (www.bmjbookshop.com/) for $£ 16.95$. The articles that made up the book are available for free on bmj.com

Richard Smith has written a book, provisionally entitled The Trouble with Medical Journals, which will be published next year by Cambridge University Press.

Competing interests: Richard Smith is editor of the BMJ and chief executive of the BMJ Publishing Group Ltd, which publishes a great deal of research, and Trisha Greenhalgh's book. He is paid a fixed salary and will not benefit financially from more people reading either the research or the book.

Richard Smith editor, BMJ, London WC1H 9JR, rsmith@bmj.com 